\title{
Distribution of juveniles of tree species along a canopy closure gradient in a tropical cloud forest of the Venezuelan Andes
}

\author{
Ana Quevedo-Rojas ${ }^{(1)}$, \\ Mauricio Jerez-Rico (2), \\ Teresa Schwarzkopf Kratzer ${ }^{(3)}$, \\ Carlos García-Núñez ${ }^{(3)}$
}

\begin{abstract}
Cloud forests represent a minor portion of the world forests, though outstanding in terms of biodiversity, endemisms, and environmental services provided. Understanding the factors that drive the regeneration and species composition of these forests, and in particular how light availability affects the patterns of juvenile tree distribution in the understory, is critical for conservation and restoration programs. In this study, we determined the range-size and overlap of the abundance distribution of juveniles for 20 tree species in an Andean tropical cloud forest in Venezuela along a gradient of percentage canopy openness (\%CO) used as a surrogate of light availability. The observed distribution of \%CO was then compared with a bounded null model of community structure in order to test light partitioning as a driver of tree species' coexistence. We measured \% $\mathrm{CO}$ using hemispherical photography and the abundance and size of juvenile trees in 280 plots of $1-\mathrm{m}$ radius spread over a 32 ha forest area. The distribution of sites was skewed towards the lower end of the \%CO gradient $(0.5$ to $12.8 \%)$, while species abundance sharply diminished at both ends of the gradient. Nevertheless, 15 out of 20 species had a non-random distribution in relation to \%CO, with many species concentrated near the lower side of the gradient. The observed pattern of species' overlap was within the $95 \%$ confidence limits for the average overlap expected under the bounded null model. These patterns indicate that low canopy openness is the rule in this forest, in spite of the scattered tree-fall gaps, and suggest that light partitioning does not determine the tree community structure at the juvenile stage. High redundancy in light requirements among juveniles of tree species may have a positive effect on species coexistence in cloud forests, thus maintaining a high species diversity. However, other factors such as recruitment limitation and differential growth/carbon-gain among species at the juvenile stage along the light gradient could contribute to the high diversity of these ecosystems.
\end{abstract}

Keywords: Natural Regeneration, Light Availability, Understory, Shade Tolerance, Hemispherical Photography, Null Models

\section{pogenic intervention (Hamilton 1995). Con- 2001).}

servation of cloud forests is of great impor- A persistent cloudiness for a large part of tance due to their high biodiversity and en- the year characterizes the tropical cloud demism, and their role in maintaining wa- forests (Ataroff 2001). Like other tropical ter balance and preventing erosive proces- forests, the environment in cloud forest ses in high mountain watersheds (Ataroff understory is very heterogeneous at spatial and temporal scales. The frequent cloudiness together with high topographic variation accentuates this heterogeneity, which imposes energetic limitations and affects other factors such as evapotranspiration, temperature and humidity (Hogan \& Machado 2002, Schwarzkopf et al. 2011).

In the understory of tropical forests, light is the main limiting resource for germination, growth, and survival (Poorter \& Arets 2003, Pearcy 2007). In these forests there is a wide light gradient from low irradiance levels $(1-2 \%)$ under closed canopies up to $25-30 \%$ in large gaps (Chazdon \& Fetcher 1984, Endler 1993). Hence, tree species have developed strategies to cope with the limitations imposed by this resource. Several researchers suggested that overlap of juveniles of tree species could explain the coexistence of a high number of species in 
tropical forests in terms of partitioning of the light environment. This partitioning has been associated with the formation of varying size gaps in the forest (Denslow 1980). Accordingly, the aim of several studies was to identify functional groups associated with the species' light requirements. For example, Bazzaz \& Pickett (1980) proposed the dichotomy between shade intolerant species requiring large amounts of light to survive and grow, and shade tolerant species. Swaine \& Whitmore (1988) proposed a simple division of tree species into two groups: pioneer or not pioneer (or climax) based on seed germination and seedling establishment. Other studies based on these functional groups focused on comparing the abundance and performance of juvenile trees between gap and nongap sites or among gaps of different size classes (Denslow 1980, 1996, Nicotra et al. 1999, Brokaw \& Busing 2000, Poorter \& Arets 2003, Wright et al. 2003). However, several of these studies found no evidence that niche partitioning explains the coexistence of many species in gaps (Brokaw \& Busing 2000, Poorter \& Arets 2003, Wright et al. 2003, De Lima \& De Moura 2008). It has been pointed out that these studies have not considered either the continuous nature of the light gradient or the fact that in a dense forest the proportion of sites with medium to large gaps is very small (Brokaw \& Busing 2000, Acevedo et al. 2001, 2003, Poorter \& Arets 2003, Lusk et al. 2006). Furthermore, the light gradient in the forest understory does not necessarily correlate with the spatial location of the gap (i.e., light can reach a point in the forest floor as direct or diffuse light), and depending on geographical and topographical factors, light beam angle and intensity can vary widely (Chazdon \& Pearcy 1991). Other authors have suggested that a considerable overlap could occur among the distribution ranges of juveniles of tree species (Lusk et al. 2006). So far, few studies have analyzed to what extent co-occurring species overlap along the light gradient (Lieberman et al. 1995, Lusk et al. 2006).

To address these problems, Lusk et al. (2006) proposed a method based on the "range-size" model (Grytnes 2003, Colwell et al. 2005) in which the forest understory light gradient is defined as a bounded domain with a "hard" lower boundary represented by absence of light and a "diffuse" upper boundary determined by the size of the largest canopy opening. According to these authors, the gradient boundaries impose constraints that influence the overlap of the range of species distributions along the gradient, despite other factors such as competition may have a large influence on community structure (Lusk et al. 2006). The average range size of the cumulative distribution of the abundance of juveniles of each species is plotted along the light gradient represented by the percentage of canopy openness (\%CO), and the average pairwise overlap of these ranges is estimated. Further, the empirical average overlap distribution is compared against a bounded null model of community structure using a resampling technique. The bounded null model assumes that: (i) domain boundaries depresses species abundance through their influence on range size. This is known as the "middomain effect" which is the increasing overlap of species ranges towards the center of a shared domain bounded by geometric constraints in relation to the distribution of species' range sizes. Towards the center of the domain occurs a peak or plateau of species richness (Colwell et al. 2005); (ii) species with optima close to domain boundaries are limited to a narrow range; and (iii) narrow ranges (in any part of the gradient) may predispose species to local extinction in dynamic understory light environments (Lusk et al. 2006). This model predicts that both density of species optima and species overlap should be highest in the domain center (intermediate light environments) and lowest close to the domain boundaries. Understanding the causes of the high tree diversity of these forests is crucial for conservation and restoration purposes. Unfortunately, there is little comprehension of the mechanisms allowing the coexistence of this high number of species, even in the most conspicuous forest component, the tree community. It is likely that, a set of processes operating at the juvenile stage largely contributes to determine tree community composition and diversity. Since light is a limiting factor in these ecosystems and juveniles are constrained to develop in their understory or to take advantage of canopy openings, we hypothesize that light gradient partitioning plays a major role in determining the tree community structure. To test this hypothesis we analyzed the range size distributions and the degree of overlap of juvenile tree species along a gradient of canopy openness for 20 tree species in an Andean cloud forest.

\section{Materials and methods}

\section{Study site}

The study was undertaken in a tract of tropical cloud forest at the San Eusebio University Forest (SEUF) in the Venezuelan Andes $\left(8^{\circ} 37^{\prime} \mathrm{N} ; 71^{\circ} 21^{\prime} \mathrm{W}\right.$ ) in Mérida state (Fig. 1a-d). Elevation ranges from 2200 to $2500 \mathrm{~m}$ a.s.l.; precipitation varies between 1400 and $1560 \mathrm{~mm}$ annually with a short dry season (December-February) and a wet season (March-November). Annual average temperature is $14.9^{\circ} \mathrm{C}$ and average photosynthetic photon flux in open sky is 1561 $\pm 77.2 \mu \mathrm{molm}^{-2} \mathrm{~s}^{-1}$ (García-Núñez et al. 1995). The forest grows on soils derived from the Colón cretacean formation characterized by stratified, massive, black, non-calcareous lutites with conchoidal fracture. The landscape consists of rounded hills, with shallow to steep slopes (Márquez 1990). The SEUF is part of the only sizable ever- green mixed (conifers and broad-leaved) forests in Venezuela (Lamprecht \& Veillón 1967). The forest is thick and rich in evergreen tree species densely covered by epiphytes, mosses, and lichens. The main tree families are Lauraceae, Melastomataceae, Guttiferae, Euphorbiaceae, Myrtaceae, and Podocarpaceae. The forest comprises various plant communities ranging from dense high forest (DHF) with complex stratification and a canopy 25-30 m high to sparse low stature forests with canopies less than $15 \mathrm{~m}$. The DHF has three layers: the upper layer approximately $25-30 \mathrm{~m}$ in height with emergent trees up to $40 \mathrm{~m}$ tall (mainly the coniferous species Retrophyllum rospigliosii), an intermediate layer $20-24 \mathrm{~m}$ in height, and a lower layer 10-19 m. The understory comprises tree seedlings and saplings, shrubs, vines, palms, and herbaceous plants. Tree ferns (Cyathea spp.) and bamboos (Chusquea spp.) are common, the latter forming dense scrubs (Schwarzkopf 2003, Ramos \& Plonczak 2007).

In the DHF, a 32 ha area was sampled to measure juvenile tree species abundance along a gradient of canopy openness. The sampling procedure consisted of a systematic virtual grid drawn from a random point selected on a vegetation map within the tract boundaries (Rangel 2004). The grid consisted of parallel transects 100 to $1000 \mathrm{~m}$ in length depending on the tract boundaries, and $100 \mathrm{~m}$ apart. Sample points were marked at $30 \mathrm{~m}$ intervals with the first point in each transect randomly chosen. We uploaded the vegetation map and the virtual grid in a Garmin GPSmap 60 $\mathrm{CSX}^{\circledast}$ using MapSetToolkit ${ }^{\circledast}$ v. 1.40 (Garmin International Inc., Olathe, KS, USA). In this way, the selected points could be reached using the shortest path, avoiding obstacles such as steep slopes, and minimizing the impact caused by the opening of access trails. A total of 30 points ( 15 in "non-disturbed" areas and 15 in "gaps") was selected randomly after discarding points in inaccessible sites (steep slopes, riverbeds). The selected points were from sites with no apparent perturbation (closed canopy, absence of fallen trees) to sites with gaps of various sizes $\left(50-500 \mathrm{~m}^{2}\right)$. Juveniles of tree species, $30-150 \mathrm{~cm}$ in height were recorded in circular plots (radius $=1 \mathrm{~m}$ ). For most species, individuals below $30 \mathrm{~cm}$ were very susceptible to death from events such as drought, flood, and pathogens. Individuals taller than $150 \mathrm{~cm}$ were discarded because light availability was measured at that height. Juveniles were measured only in the rainy season (1975 individuals). For each individual we recorded species name and total height. Around points placed in non-disturbed areas, eight plots were established in a circular $200 \mathrm{~m}^{2}$ area (120 plots). The gaps were delimited following the method proposed by Brokaw \& Busing (2000) and the plots were distributed from border to gap center (16o total plots). In each plot, a hemispherical photograph was taken in 

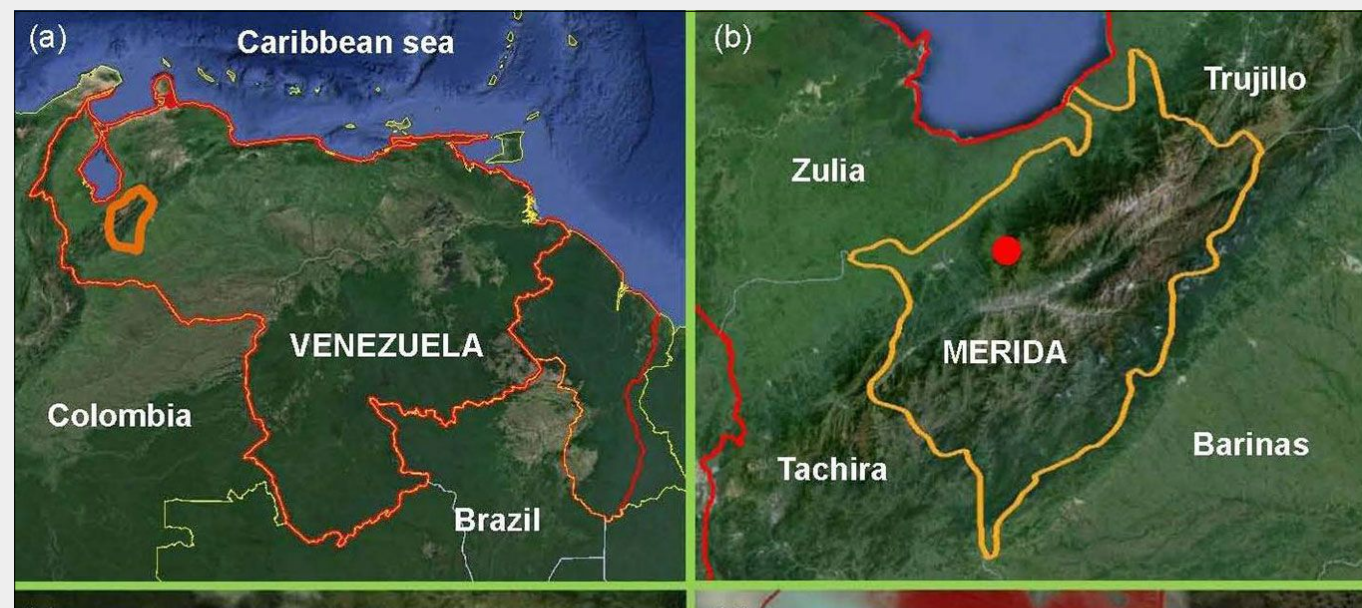

Fig. 1 - Study site location. Satellite images including the boundaries of (a) Venezuela; (b) Mérida State; (c) San Eusebio University Forest (SEUF); and (d) study site ca. 32 ha (Images from Google Earth v5.0 July, 2013).
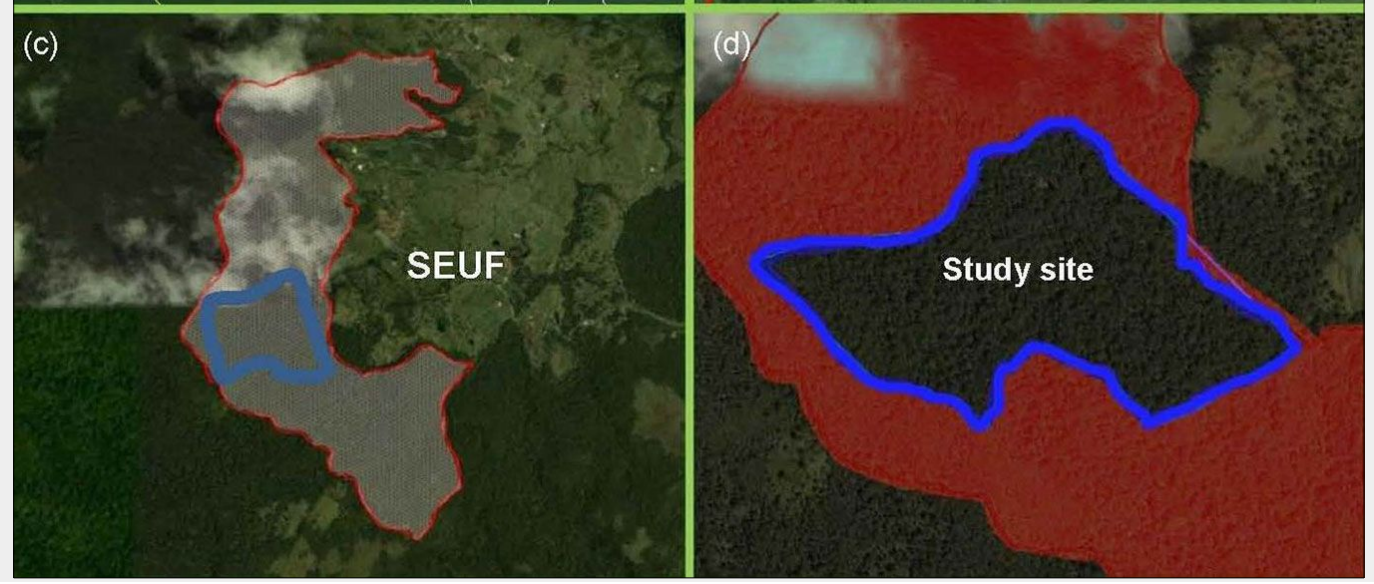

both dry (February) and rainy (October) seasons of 2010.

\section{Hemispherical photographs}

Hemispherical photography is one among several techniques used for estimating light availability and canopy structure. The principle of this method is that a fish eye lens captures an image that spans a $180^{\circ}$ arc, and when pointed vertically can capture all possible angles of incoming light (Brusa \& Bunker 2014). Other popular methods include the LAl-2000 ${ }^{\circledR}$ (plant canopy analyzer - Li-cor, Lincoln, NE, USA), spherical densitometers, AccuPAR ${ }^{\circledast}$ ceptometer (Decagon Devices, Pullman, WA, USA), LIDAR, TRAC (Tracing radiation and architecture of canopies), and photosensitive diazo paper (Jonckheere et al. 2004, Chianucci \& Cutini 2012, Brusa \& Bunker 2014). There are several methods to determine light and canopy properties under a set of environmental conditions and ecosystems. Each method has advantages and disadvantages for estimating the various components of light availability and canopy structure. Some of them are very costly (e.g., LIDAR, LAI2000), others although cheap (e.g., densitometers, photosensitive diazo paper) are strongly subjective (Brusa \& Bunker 2014). Hemispherical photography is an option of intermediate cost that has several advantages such as a spatial discrimination, acquisition of foliage angular distribution, and gap fractions at different zenith and azimuthal angles. Digital hemispherical photography is becoming less expensive, and images can be acquired easily. Also, they can be stored as permanent records, making it possible to get repeated records over time of the variation in light and canopy properties of the same point (Chen \& Black 1991, Chianucci \& Cutini 2012). However, hemispherical photographs have several disadvantages such as the need for certain environmental conditions to enable photographs to be taken (overcast sky), correct exposure, including diaphragm aperture, time of exposure, correction of lens distortion, and tedious work in processing the images (Zhang et al. 2005, Inoue et al. 2004). Nonetheless, the continuous progress in digital camera technology, software for processing raw data and efforts to standardize protocols of image acquisition and processing make this one of the most promising methods for analyzing light availability and canopy properties.

We took hemispherical photographs to estimate the percentage of canopy openness at the center of each plot using a 10 Mp digital camera Nikon COOLPIX ${ }^{\circledast}$ P5000 with a "Fisheye Converter" Nikon FC-E8 with a $183^{\circ}$ optical field. The camera was mounted on a tripod and leveled with the top of the lens standing $150 \mathrm{~cm}$ above the ground. We took photographs only in overcast conditions using an appropriate degree of exposure following the protocol proposed by Zhang et al. (2005). For image processing, we used Gap Light Analyzer (GLA) v. 2.0 (Frazer et al. 1999). We corrected the lens distortion (from $183^{\circ}$ to $180^{\circ}$ ) with a third degree polynomial equation (Frazer et al. 2001 - eqn. 1):

$Y=6.638 \cdot X-0.0025 \cdot X^{2}-(2.4014 \mathrm{E}-0.5) X^{3}$

where $Y$ is the radial position of a projected point measured in pixels from the optical center of a full resolution digital image $(1600 \times 1200$ pixels $)$ and $X$ is the angular distance $\left(0^{\circ} \leq X \leq 90^{\circ}\right)$. For differentiating sky from vegetation pixels, we used the software SIDELOOK (Nobis \& Hunziker 2005). We selected the blue channel to maximize pixel differentiation. The software automatically transforms the images $(n=560)$ to black and white and generates the optimal threshold for differentiating between sky and vegetation pixels. For each optimized image, GLA computes a set of variables related to light environment and canopy structure. As inputs, GLA requires: latitude, longitude, altitude, growing season interval, slope, cloudiness index, solar constant, and spectral fraction of the study site. The program simulates the potential amount of light that would reach a given point on the forest floor throughout the growing season and generates several outputs such as \%CO among other variables.

\section{Juvenile tree distribution along the} light gradient

The percentage of canopy openness (\%CO) was used as a surrogate of the light environment (Poorter \& Arets 2003, Lusk et al. 2006, Whitfeld et al. 2014). It is de- 
fined as the percentage of sky that can be seen from below the canopy (Frazer et al. 1999). This variable is widely used because it is easy to measure without the need for costly devices. In many forests, there is a strong bias towards sites with \%CO $\leq 5 \%$ (Montgomery \& Chazdon 2002, Lusk et al. 2006), thus almost everywhere the \%CO is very low. Therefore, a large proportion of the forest is favorable for regeneration of shade tolerant species, but few places exist in which light demanding species can regenerate. Given the large areas for growth of shade tolerant species, small differences in light requirements could suffice to avoid competitive exclusion and allow the coexistence of populations of numerous species. To avoid underestimating the relative abundance of species at the upper end of the light gradient, the plots were ordered from low to high values of \%CO and transformed to a percentage scale (i.e., $0 \%$ for the lowest value and $100 \%$ for the highest). Therefore, equal intervals in the transformed \% $\mathrm{CO}$ scale represent equal areas of microsite availability. The median and interquartile range (IQR) of the distribution of each species was represented over the axis of the transformed gradient of \%CO. The sum of all species' individuals produces the accumulated distribution for the whole forest. The IQR is a robust indicator of species' distribution since it excludes extreme values at both extremes of the gradient (Lusk et al. 2006). A goodness of fit Kolmogorov-Smirnov test was used to detect non-randomness in the IQR of the abundance distribution of each species against the cumulative empirical distribution of the \%CO for the whole forest. If the $\mathrm{p}$-value for a species is $\geq 0.05$, then its abundance distributes randomly along the $\% \mathrm{CO}$ gradient, i.e., the light environment has no effect on the distribution of juveniles of that species Lusk et al. (2006).

For comparing the average pairwise over-

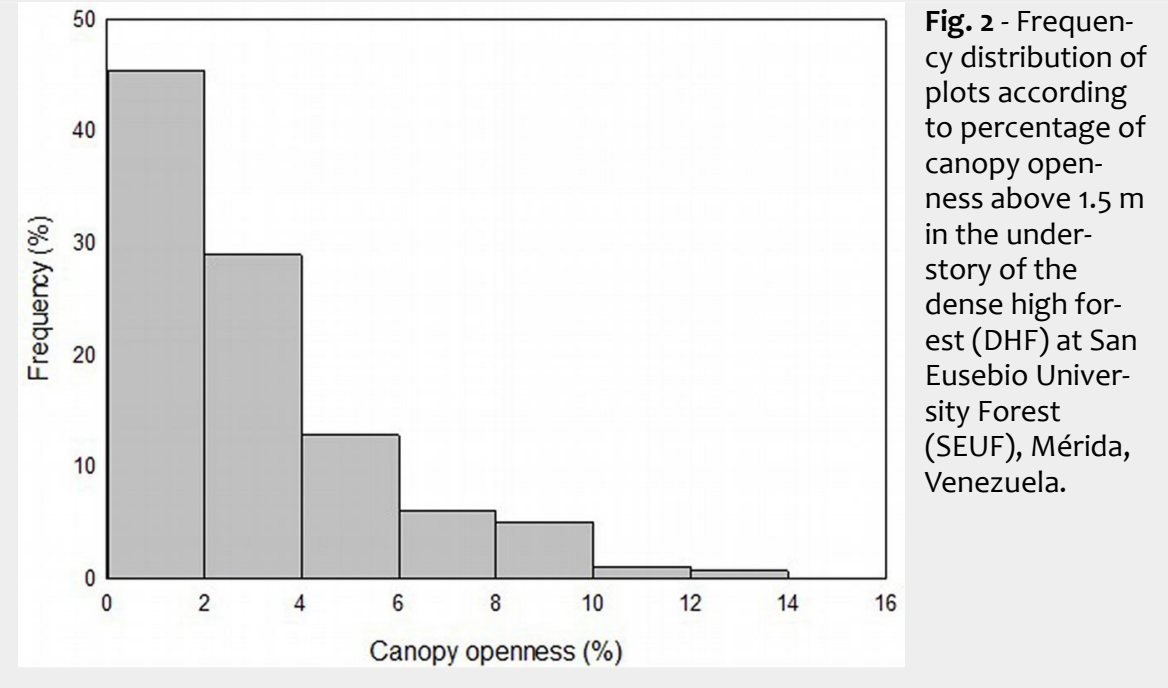

lap of the empirical species IQR on the rank-transformed canopy openness with the proposed bounded null model, we used the Mid-domain Null Monte Carlo simulation procedure (McCain 2004) to generate $95 \%$ confidence intervals for the predicted average pairwise overlap interquartile distribution from the null model based on the midpoints of the empirical species distributions. We ran 1000 simulations using resampling with replacement. If the empirical pattern of the predicted average pairwise overlap departs strongly from the confidence limits for the null model distribution, then the results should be consistent with the hypothesis that there is a partitioning of the light environment by the juveniles of tree species along the gradient of \%CO.

\section{Results}

\section{Percentage of canopy openness}

More than $75 \%$ of the plots showed a \%CO $\leq 4.5 \%$ and $50 \%$ had a $\% \mathrm{CO} \leq 2.2 \%$. Maximum
\%CO was $12.6 \%$ (Fig. 2). There were no statistically significant differences in \%CO between the rainy and dry seasons ( $p=$ 0.134 , paired student $t$-test, $n=280$ ).

\section{Juvenile distribution on the \%CO gradient}

The Kolmogorov-Smirnov test showed that only five of 20 species (only those species with at least 10 individuals were included) had their juveniles randomly distributed in relation to \%CO ( $p>0.05)$ : Myrcianthes karsteniana, Myrcia fallax, Aegiphila terniflora, Roupala obovata and Psicotria spp. (Tab. 1). All the others had clearly non-random distributions with $p$-values well below 0.05 . This suggests a certain degree of light partitioning by the juveniles of tree species. The abundance IQRs show that a high number of species concentrate in a \%CO $\leq 6.6 \%$ (Fig. 3). The abundance IQR of all combined species (identified as "Forest" in Fig. 3) matched approximately with the IQR of the ordered samples (i.e., between 1.3 and $4.2 \%(\mathrm{CO})$, and the mid-

Tab. 1 - Non-randomness Kolmogorov-Smirnov test of juvenile tree species distribution along the percentage of canopy openness gradient in the experimental area at SEUF, Mérida, Venezuela.

\begin{tabular}{llcc}
\hline Species & Family & Abbreviation & P-value \\
\hline Hyeronima moritziana & Euphorbiaceae & $\mathrm{Hm}$ & $<0.001$ \\
Ocotea macropoda & Laureaceae & $\mathrm{Om}$ & $<0.001$ \\
Beilshmiedia sulcata & Laureaceae & $\mathrm{Bs}$ & $<0.001$ \\
Tetrorchidium rubrivenium & Euphorbiaceae & $\mathrm{Tr}$ & $<0.001$ \\
Retrophyllum rospigliosii & Podocarpaceae & $\mathrm{Rr}$ & $<0.001$ \\
Myrcia acuminata & Myrtaceae & $\mathrm{Ma}$ & $<0.001$ \\
Oreopanax capitatus & Araliaceae & $\mathrm{Oc}$ & $<0.001$ \\
Billia colombiana & Hippocastanaceae & $\mathrm{Bc}$ & $<0.001$ \\
Cyathea spp & Cyatheaceae & $\mathrm{Csp}$ & $<0.001$ \\
Oreopanax reticulatus & Araliaceae & $\mathrm{Or}$ & $<0.001$ \\
Passiflora lindeniana & Passifloraceae & $\mathrm{Pl}$ & $<0.001$ \\
Miconia meridensis & Melastomataceae & $\mathrm{Mm}$ & 0.001 \\
Casearia tachirensis & Flacourtiaceae & $\mathrm{Ct}$ & 0.003 \\
Prunus moritziana & Rosaceae & $\mathrm{Pm}$ & 0.004 \\
Eugenia sp. & Myrtaceae & $\mathrm{Esp}$ & 0.006 \\
Myrcia fallax & Myrtaceae & $\mathrm{Mf}$ & 0.051 \\
Roupala obovata & Proteaceae & $\mathrm{Ro}$ & 0.093 \\
Myrcianthes karsteniana & Myrtaceae & $\mathrm{Mk}$ & 0.205 \\
Psicotria spp. & Rubiaceae & $\mathrm{Psp}$ & 0.247 \\
Aegiphila terniflora & Verbenaceae & $\mathrm{At}$ & 0.295 \\
\hline
\end{tabular}


Fig. 3 - Interquartile ranges of juvenile tree species' distribution on the rank transformed gradient of percentage of canopy openness (280 plots, 1975 individuals). Letters identify-

ing ranks are species abbreviations and their position correspond to the median (midpoint) of the abundance distribution of juvenile trees.

For abbreviations, see Tab. 1.
Canopy openness (\%)

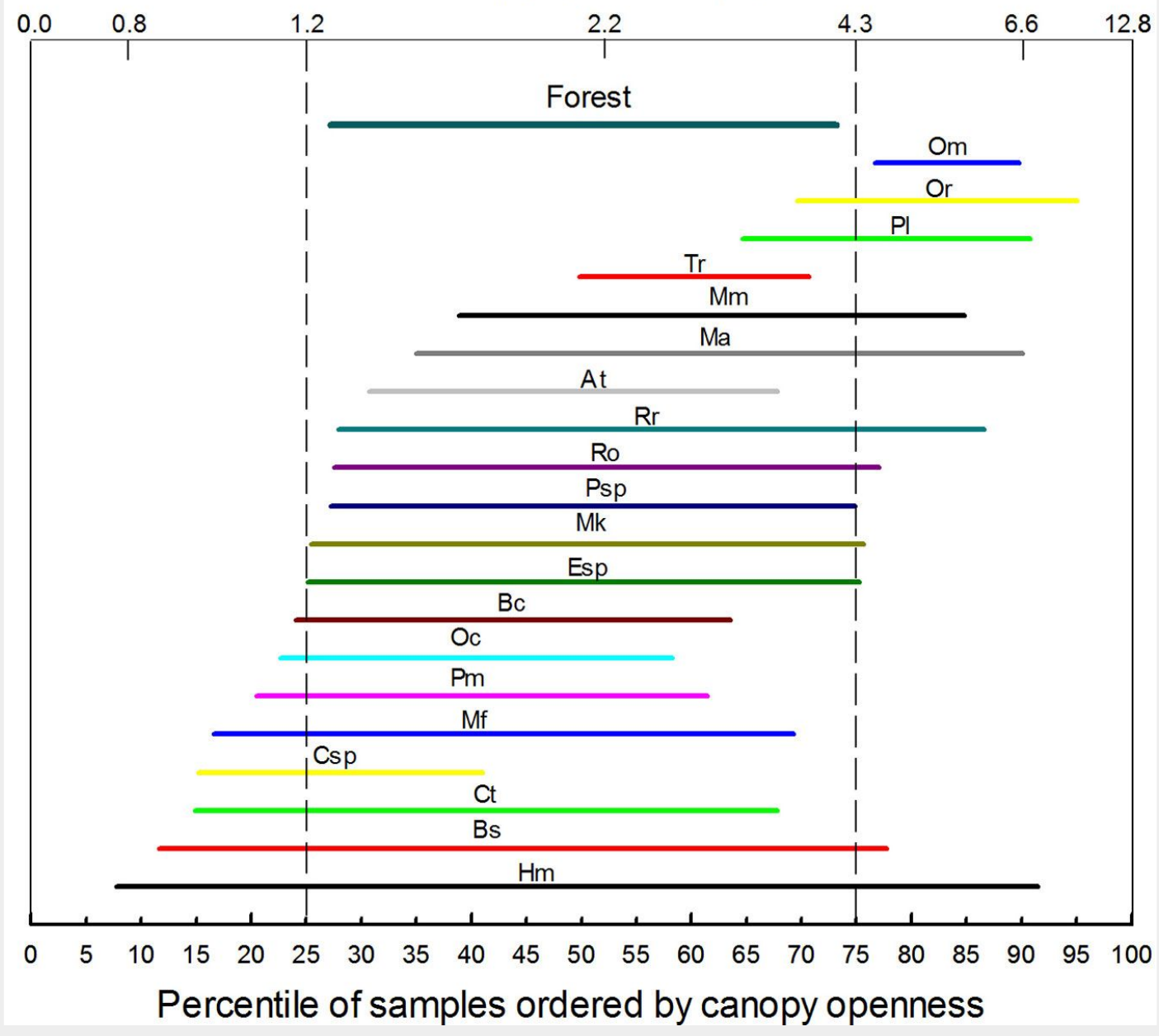

point (median) of 17 species is within this range. Only three species (Ocotea macropoda, Oreopanax reticulatus, and Passiflora lindeniana) had their median outside this range. Also, four species (Aegiphila terniflora, Eugenia spp., Myrcianthes karsteniana, and Psicotria spp.) showed IQRs similar to that for the whole forest, suggesting an intermediate distribution along the \% CO gradient. Beilshmiedia sulcata and Hyeronima moritziana had a wide IQR, suggesting that these species perform relatively well along the \%CO gradient. Although several species' IQR lower-ends are below the $25^{\text {th }}$ percentile of \% CO, only the tree fern Cyathea spp. has its midpoint close to such limit. This could indicate that below $1.2 \% \mathrm{CO}$ there are strong limitations for the survival and growth of tree species. On the other hand, above $4.4 \%$ CO juvenile tree species seem to face growth limitations.

\section{Null model of community structure}

The average empirical distribution of pairwise overlap of species' IQRs was well within the upper and lower $95 \%$ confidence limits generated by the bounded null model of community structure (Fig. 4). Species richness (represented by the overlap of IQRs) peaked at nearly $2.2 \%$ canopy openness, close to the median \%CO.

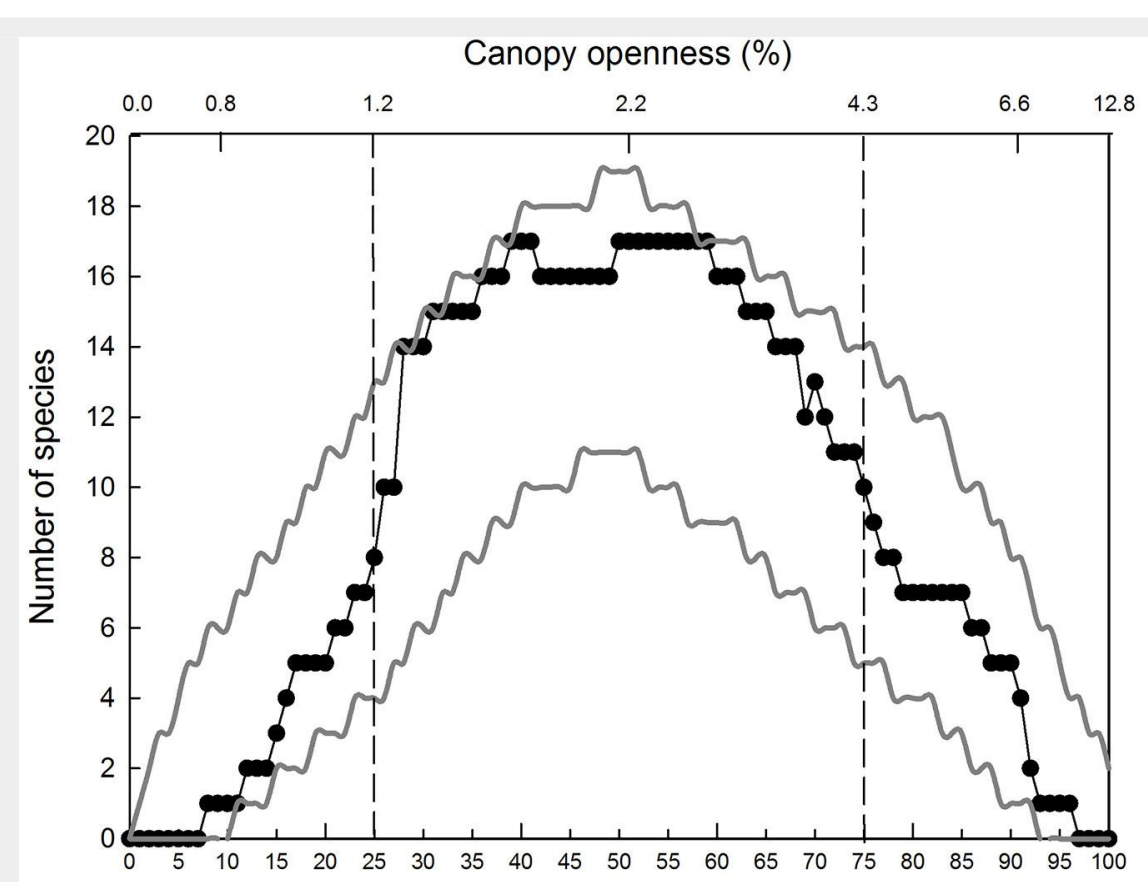

Percentile of samples ordered by canopy openness

Fig. 4 - Empirical distribution of species richness along the canopy openness gradient. Empirical distribution of species richness along the canopy openness gradient (unbroken line) and $95 \%$ confidence limits for the average distribution predicted by the bounded null model (dotted lines). 


\section{Discussion}

The range size for untransformed percentage of canopy openness from $0.5 \%$ to $12.8 \%$ is similar to the results found in other studies (Lieberman et al. 1995, Figueroa \& Lusk 2001, Poorter \& Arets 2003, Lusk et al. 2006, Moll-Rocek et al. 2014). Poorter \& Arets (2003) compared 15 studies carried out with different measurement techniques in tropical forests around the world reporting average values of \%CO between 0.7 and $4.3 \%$ and maxima between 10 and $20 \%$. In the majority of forests, either tropical or temperate, the frequency distribution of light environments is biased towards microsites with less than $5 \%$ canopy openness (Montgomery \& Chazdon 2002, Lusk et al. 2006). Ostertarg (1998) estimated for Costa Rican lowland forest an average \% $\mathrm{CO}$ of 7.3 in gaps and 3.9 under closed canopy. Studies for the cloud forest have shown lower than average values of $\%$ CO. For example, in an Andean cloud forest, Acevedo et al. (2003) found a \%CO ranging from $3.4 \%$ to $9.5 \%$. In a cloud forest of Southeast Brazil, De Carvahlo \& De Oliveira-Filho (2001) found a range of \%CO from 5 to $18 \%$ in 31 gaps $50-70 \mathrm{~m}^{2}$ in size. In the tropical cloud forest, low \%CO is probably related to the complex vertical structure, which is composed of at least three dense layers, and abundant epiphytes intercepting a large part of the solar radiation.

In general, the pattern of abundance distribution of tree species was nonrandom in relation to the light environment, but with a high overlap within the interquartile range of \%CO. Species abundance was strongly depressed towards both extremes of the $\mathrm{IQR}$ of \%CO, whereas the highest number of species had IQRs overlapping around the median \%CO. The empirical pattern of species' IQR overlap did not depart from the confidence limits established for the average overlap expected under the assumptions of the null model of community structure. This supports the results found in other studies that the observed differences in niche expression along the \%CO gradient do not necessarily imply species coexistence (Lusk et al. 2006). Thus, the majority of species in this forest appears to be of intermediate shade tolerance. Figueroa \& Lusk (2001) found that the average light environment for 13 of 26 species occurred between 4 and $12 \%$ of \% CO in a temperate Chilean forest. Wright et al. (2003) evaluated 73 abundant species in Barro Colorado Island (Panamá) and examined the hypothesis that under closed canopies, morphology and physiology determine shade tolerance. They did not find a high number of species functionally equivalent in the extremes of the regeneration gradient, and rather a few species, either clearly shade tolerant or clearly light demanding. Most species had intermediate light requirements. The authors suggested that juveniles of light demanding tree species are relatively rare because they are ephemeral, die quickly in high shade, or they grow fast to larger sizes if light levels remain high. In contrast, shade tolerant species are relatively abundant in the juvenile phase because they are persistent, and survive and grow slowly under shade. Our results show that juveniles of tree species in this forest have low abundances in the upper boundary of the light environment in large canopy gaps. Additional evidence comes from physiological and morphological features measured during a shade house experimental study (Quevedo RA, unpublished data) showing that juveniles of several tree species growing under low shade have low growth rates, low photosynthetic rates, and high susceptibility to photoinhibition. These results are important for an understanding of limitations and the determination of strategies for preserving and restoring tree diversity in these ecosystems.

Although 15 of the 20 studied species showed a non-random distribution along the canopy openness gradient, suggesting some degree of light partitioning, the test based on the bounded null model indicated that the community fits within the confidence interval for the null model, meaning that species' range overlap did not deviate significantly from a random pattern. Moreover, species on the lower half of the gradient tend to have wide distribution ranges along the \% $\mathrm{CO}$ gradient, and most species have a wide distribution range and midpoint placed towards the center of the gradient ( 16 species between the $35^{\text {th }}$ and $65^{\text {th }}$ percentile, whereas only three species have ranges outside the IQR of \%CO located near the upper boundary. These patterns suggest that in this forest, not only low canopy openness is the rule in spite of scattered tree fall gaps, but also, that light partitioning does not determine tree community structure at the tree juvenile stage, rather there is a strong niche overlap in relation to light availability. The three species with IQR close to the upper boundary of the light gradient cannot be considered truly pioneer species, as their abundances peak between 4 and $6.6 \% \mathrm{CO}$. Possibly, given the complex vertical structure of these ecosystems, the diffuse radiation gradient would be more efficient in detecting light demanding species.

High redundancy in light requirements among juveniles of tree species may have a positive effect on species' coexistence in cloud forests and, therefore, in the maintenance of a high species diversity. However, other factors such as recruitment limitation (Hubbell et al. 1999) and differential growth/carbon-gain among species at the juvenile stage along the \% CO range shown in this study would contribute to understanding the causes of the high diversity of these ecosystems and ways to preserve them.

\section{Acknowledgements}

The authors wish to thank Dr. Ken Green from the Australian Institute of Alpine Studies and an anonymous reviewer for their helpful and insightful comments, which helped us to improve the manuscript. Also, to Professor Luis E. Gámez from the Botany Laboratory (ULA) for his help in botanical species identification and to the SEUF field guides Ancelmo Dugarte and Dani Dugarte for helping in field species identification and field work. This work was funded by the grant Fo-703-10-01A from CDCHTA of Universidad de Los Andes (ULA), Venezuela, and Scholarship 200601148 from Misión Ciencia-FONACIT, Venezuela. We acknowledge the support of the Institute for Forestry Development (INDEFOR-ULA) for field support at the San Eusebio University Forest.

\section{References}

Acevedo M, Monteleone S, Ataroff M, Estrada C (2001). Aberturas del dosel y espectro de la luz en el sotobosque de una selva nublada andina de Venezuela [Canopy gaps and understory light spectrum in a Venezuelan Andean cloud forest]. Ciencia 9: 165-183. [in Spanish]

Acevedo M, Ataroff M, Monteleone S, Estrada C (2003). Heterogeneidad estructural y lumínica del sotobosque de una selva nublada andina de Venezuela [Light and structural heterogeneity in the understory of a Venezuelan Andean cloud forest]. Interciencia 28: 394-403. [in Spanish]

Ataroff M (2001). Venezuela. In: "Bosques Nubla dos del Neotrópico" (Kappelle M, Brown A eds). INBio, Costa Rica, pp. 397- 442. [in Spanish]

Bazzaz F, Pickett S (1980). Physiological ecology of tropical succession: a comparative review. Annual Review of Ecology and Systematics 11: 287-310. - doi: 10.1146/annurev.es.11.110180.0014 43

Brokaw N, Busing R (2000). Niche versus chance and tree diversity and forest gaps. Trends in Ecology and Evolution 15: 183-188. - doi: 10.1016/ S0169-5347(00)01822-X

Brown AD, Kappelle M (2001). Introducción a los bosques nublados del neotrópico: una síntesis regional. In: "Bosques nublados del neotrópico” (Kappelle M, Brown A eds). INBio, Costa Rica, pp. 697. [in Spanish]

Brusa A, Bunker DE (2014). Increasing the precision of canopy closure estimates from hemispherical photography: blue channel analysis and under-exposure. Agricultural and Forest Meteorology 195-196: 102-107. - doi: 10.1016/j. agrformet.2014.05.001

Chazdon RL, Pearcy W (1991). The importance of sunflecks for forest understory plants. BioScience 41: 760-766. - doi: 10.2307/1311725

Chazdon RL, Fetcher N (1984). Photosynthetic light environments in a lowland tropical rain forest in Costa Rica. Journal of Ecology 72: 553 564. - doi: $10.2307 / 2260066$

Chianucci F, Cutini A (2012). Digital hemispherical photography for estimating forest canopy properties: current controversies and opportunities. iForest - Biogeosciences and Forestry 5: 290-295. - doi: 10.3832/iforo775-005

Chen JM, Black TA (1991). Measuring leaf area index of plant canopies with branch architec- 
ture. Agricultural and Forest Meteorology 57: 112. - doi: 10.1016/0168-1923(91)90074-Z

Colwell R, Rahbek C, Gotelli N (2005). The middomain effect: there's a baby in the bathwater. The American Naturalist 166: 149-154. - doi: $10.1086 / 491689$

De Carvahlo LMT, De Oliveira-Filho AT (2001). Distribution, size and dynamics of canopy gaps in a cloud forest of the Ibitipoca range, southeastern Brazil. In: "Life forms and dynamics in tropical forest” (Gottsberger G, Liede S eds). Dissertationes Botanicae, Berlin-Stuttgart, Germany, pp. 29-39.

De Lima RA, De Moura LC (2008). Gap disturbance regimen and composition in the Atlantic Montane Rain Forest. Plant Ecology 197: 239253. - doi: $10.1007 /$ s11258-007-9374-x

Denslow JS (1980). Gap partitioning among tropical rainforest tree. Biotropica 12 (2):47-55. [online] URL: http://www.jstor.org/stable/2388 156

Denslow JS (1996). Functional groups diversity and responses to disturbance. In: "Biodiversity and Ecosystem Processes in Tropical Forests" (Orians G, Dirzo R, Cushman JH eds). SpringerVerlag, Berlin, Germany, vol. 122, pp. 127-151.

Endler JA (1993). The color of light in forests and its implications. Ecological Monographs 63: 127. - doi: 10.2307/2937121

Figueroa JA, Lusk CH (2001). Germination requirements and seedling shade tolerance are not correlated in a Chilean temperate rain forest. New Phytologist 152: 483-489. - doi: 10.1046/j. 0028-646X.2001.00282.x

Frazer G, Canham C, Lertzman KP (1999). Gap light analyzer (GLA), version 2.0: imaging software to extract canopy structure and gap light transmission indices from true-color fisheye photographs, user manual and program documentation. Simon Frazer University, Burnaby, British Columbia, Canada, and Institute of Ecosystem Studies, Millbrook, New York, USA, pp. 34. [online] URL: http://rem-main.rem.sfu. ca/forestry/downloads/Files/GLAV2UsersManua I.pdf

Frazer G, Fournier R, Trofymow J, Hall R (2001). A comparison of digital and film fisheye photography for analysis of forest canopy structure and gap light transmission. Agricultural and Forest Meteorology 109: 249-263. - doi: 10.1016/S0168-1923(01)00274-X

García-Núñez C, Azócar A, Rada F (1995). Photosynthetic acclimation to light in juveniles of two cloud forest tree species. Tree 10: 114-124. doi: 10.1007/BF00192192

Grytnes JA (2003). Ecological interpretation of the mid-domain effect. Ecology Letters 6: 883888. - doi: 10.1046/j.1461-0248.2003.00511.x

Hamilton LS (1995). Mountain cloud forest conservation and research: a synopsis. Mountain Research and Development 15: 259-266. - doi: $10.2307 / 3673933$

Hogan KP, Machado JL (2002). La luz solar: consecuencias biológicas y su medición [Sun light: biological consequences and its measurement]. In: “Ecología y Conservación de Bosques Neo- tropicales" (Kattan G, Guariguata MR eds). Libro Universitario Regional, EULAC-GTZ, Costa Rica, pp. 119-143. [in Spanish]

Hubbell SP, Foster RB, O’Brien ST. Harms KE, Condit R, Wechsler B, Wright SJ, Lao L (1999). Light-gap disturbances, recruitment limitation, and tree diversity in a neotropical forest. Science 283: 554-557. - doi: 10.1126/science.283.5401. 554

Inoue A, Yamamoto K, Mizoue N, Kawahara $\mathrm{Y}$ (2004). Effects of image quality, size and camera type on forest light environment estimates using digital hemispherical photography. Agricultural and Forest Meteorology 126 (1-2): 8997. - doi: 10.1016/j.agrformet.2004.06.002

Jonckheere I, Fleck S, Nackaerts K, Muys B, Coppin P, Weiss M, Baret F (2004). Review of methods for in situ leaf area index determination. Part I. Theories, sensors and hemispherical photography. Agricultural and Forest Meteorology 121: 19-35. - doi: 10.1016/j.agrformet.2003. 08.027

Lamprecht H, Veillón JP (1967). La carbonera. EI Farol 1: 17-24. [in Spanish]

Lieberman M, Lieberman D, Peralta R (1995). Canopy closure and distribution of tropical forest tree species in La Selva, Costa Rica. Journal of Tropical Ecology 11: 161-178. - doi: 10.1017/So2 66467400008609

Lusk CH, Chazdon R, Hofmann G (2006). A bounded null model explains juvenile tree community structure along light availability gradients in a temperate rain forest. Oikos 112: 131137. - doi: 10.1111/j.0030-1299.2006.13922.x

Márquez O (1990). Génesis de una secuencia de suelos en el Bosque Experimental San Eusebio, La Carbonera, Estado Mérida [Genesis of a soil sequence in the San Eusebio Experimental Forest, La Carbonera, Mérida State]. Revista Forestal Venezolana 32: 133-150. [in Spanish]

McCain CM (2004). The mid-domain effect applied to elevational gradients: species richness of small mammals in Costa Rica. Journal of Biogeography 31: 19-31. - doi: 10.1046/j.0305-0270. 2003.00992.x

Moll-Rocek J, Gilbert M, Broadbent E (2014). Brazil nut (Bertholletia excelsa, Lecythidaceae) regeneration in logging gaps in the Peruvian Amazon. International Journal of Forestry Research 2014: 1-8. - doi: 10.1155/2014/420764

Montgomery RA, Chazdon RL (2002). Light gradient partitioning by tropical tree seedlings in the absence of canopy gaps. Oecologia 131: 165174. - doi: 10.1007/s00442-002-0872-1

Nicotra AB, Chazdon RL, Iriarte SVB (1999). Spatial heterogeneity of light and woody seedling regeneration in tropical wet forest. Ecology 80 : 1908-1926. - doi: 10.1890/0012-9658(1999)080 [1908:SHOLAW]2.0.CO;2

Nobis M, Hunziker U (2005). Automatic thresholding for hemispherical canopy-photographs based on edge detection. Agricultural and Forest Meteorology 128: 243-250. - doi: 10.1016/j.agrformet.2004.10.002

Ostertarg R (1998). Belowground effects of canopy gaps in a tropical wet forest. Ecology 79:
1294-1304. - doi: 10.1890/0012-9658(1998)079 [1294:BEOCGI]2.0.CO;2

Pearcy RW (2007) Responses of plants to heterogeneous light environments. In: "Functional Plant Ecology ( $2^{\text {nd }}$ edn)" (Valladares F, Pugnaire F eds). Marcel Dekker, New York, USA, pp. 370305.

Poorter L, Arets EJM (2003). Light environment and tree strategies in a Bolivian tropical moist forest: an evaluation of the light partitioning hypothesis. Plant Ecology 166: 295-306. - doi: 10.1023/A:1023295806147

Ramos MC, Plonczak MA (2007). Dinámica sucesional del componente arbóreo luego de un estudio destructivo de biomasa en el Bosque Universitario San Eusebio, Mérida Venezuela [Arboreal component succesional dynamics after a destructive study of biomass, in San Eusebio University Forest, Mérida-Venezuela]. Revista Forestal Venezolana 51: 35-46. [in Spanish]

Rangel C (2004). Mapa de vegetación escala 1:5000 y visualización tridimensional de la Estación Experimental San Eusebio por medio de sistemas de información geográfica y animaciones virtuales [Vegetation map 1:5000 scale and tridimensional visualization of the San Eusebio Experimental Station through a geographic information system and virtual animations]. Master Thesis, Centro de Estudios Forestales y Ambientales de Postgrado, Universidad de Los Andes, Mérida, Venezuela, pp. 51. [in Spanish]

Schwarzkopf T, Riha SJ, Fahey TJ, DeGloria S (2011). Are cloud forest tree structure and environment related in the Venezuelan Andes? Austral Ecology 36: 280-289. - doi: 10.1111/j.1442-99 93.2010.02160.x

Schwarzkopf T (2003). Biophysical characterization of cloud forest vegetation in the Venezuelan Andes. Ph.D. Thesis, Cornell University, Ithaca, NY, USA, pp. 173.

Swaine MD, Whitmore TC (1988). On the definition of ecological species groups in tropical rain forest. Vegetatio 75: 81-86. - doi: 10.1007/BFooo 44629

Vareschi V (1992). Ecología de la vegetación tropical [Tropical vegetation ecology]. Sociedad Venezolana de Ciencias Naturales, Caracas, Venezuela, pp. 306. [in Spanish]

Whitfeld T, Lodge A, Roth A, Reich P (2014). Community phylogenetic diversity and abiotic site characteristics influence abundance of the invasive plant Rhamnus cathartica L. Journal of Plant Ecology 7: 202-209. - doi: 10.1093/jpe/rt to20

Wright SJ, Muller-Landau HC, Condit R, Hubbell SP (2003). Gap-dependent recruitment, realized vital rates, and size distributions of tropical trees. Ecology 84:3174-3185. - doi: 10.1890/020038

Zhang YC, Jing M, Miller JR (2005). Determining digital hemispherical photograph exposure for leaf area index estimation. Agricultural and Forest Meteorology 133: 166-181. - doi: 10.1016/j. agrformet.2005.09.009 